\title{
Selection and characterization of alanine racemase inhibitors against Aeromonas hydrophila
}

\author{
Yaping Wang ${ }^{1}$, Chao Yang ${ }^{2}$, Wen Xue ${ }^{1}$, Ting Zhang ${ }^{1}$, Xipei Liu', Jiansong Ju', Baohua Zhao ${ }^{*}$ and Dong Liu*
}

\begin{abstract}
Background: Combining experimental and computational screening methods has been of keen interest in drug discovery. In the present study, we developed an efficient screening method that has been used to screen 2100 small-molecule compounds for alanine racemase Alr-2 inhibitors.

Results: We identified ten novel non-substrate Alr-2 inhibitors, of which patulin, homogentisic acid, and hydroquinone were active against Aeromonas hydrophila. The compounds were found to be capable of inhibiting Alr-2 to different extents with $50 \%$ inhibitory concentrations $\left(I_{50}\right)$ ranging from 6.6 to $17.7 \mu \mathrm{M}$. These compounds inhibited the growth of A. hydrophila with minimal inhibitory concentrations (MICs) ranging from 20 to $120 \mu \mathrm{g} / \mathrm{ml}$. These compounds have no activity on horseradish peroxidase and D-amino acid oxidase at a concentration of $50 \mu \mathrm{M}$. The MTT assay revealed that homogentisic acid and hydroquinone have minimal cytotoxicity against mammalian cells. The kinetic studies indicated a competitive inhibition of homogentisic acid against Alr- 2 with an inhibition constant $\left(K_{\mathrm{i}}\right)$ of $51.7 \mu \mathrm{M}$, while hydroquinone was a noncompetitive inhibitor with a $K_{\mathrm{i}}$ of $212 \mu \mathrm{M}$. Molecular docking studies suggested that homogentisic acid binds to the active site of racemase, while hydroquinone lies near the active center of alanine racemase.
\end{abstract}

Conclusions: Our findings suggested that combining experimental and computational methods could be used for an efficient, large-scale screening of alanine racemase inhibitors against $A$. hydrophila that could be applied in the development of new antibiotics against A. hydrophila.

Keywords: Aeromonas hydrophila, Alanine racemase, Inhibitor, Molecular docking

\section{Background}

Aeromonas hydrophila is a gram-negative facultative anaerobic bacterium of major public health concern that causes a variety of diseases in both fish and humans, resulting in severe economic losses [1]. Extensive antibiotic use has led to antibiotic resistance, which can potentially be transferred to other aquatic bacteria and human pathogenic bacterial strains [2].

Thus, there is considerable interest in the identification and development of targets for drug design. One such target is alanine racemase [3, 4]. Alanine racemase (EC 5.1.1.1) is a pyridoxal-5'-phosphate (PLP)-containing homodimeric enzyme that catalyzes the interconversion of L-alanine to

\footnotetext{
* Correspondence: baohua519@163.com; pqw1234@163.com

${ }^{1}$ College of Life Science, Hebei Normal University, Shijiazhuang, China

Full list of author information is available at the end of the article
}

D-alanine [5]. D-Alanine is an essential building block of the cell wall of both gram-positive and gram-negative bacteria. There are no known homologs of alanine racemases in humans, but because they are ubiquitous among prokaryotes, they make an attractive antimicrobial target $[6,7]$.

Numerous inhibitors, such as $O$-carbamyl-D-serine, D-cycloserine, $\beta, \beta$-trifluoroalanine, alanine phosphonate, L-amino-cyclopropane phosphonate, and $\beta$-chloroand $\beta$-fluoro alanine, were identified as able to affect the activity of alanine racemase $[8,9]$. All of these inhibitors were structural analogs of alanine: they interact with the enzyme-bound PLP and interfere with the catalytic process of the enzyme, but they lack target specificity with a tendency to inactivate other unrelated PLP-dependent enzymes, leading to cellular toxicity [10]. PLP-related offtarget effects could be overcome by using enzyme inhibitors that are not substrate analogs. 
The PLP cofactor enables the enzyme to lower the pKa of the $\alpha$-proton by stabilizing the attendant carbanion using a substrate-bound external aldimine [11]. The majority of substrate analogs, such as D-cyloserine, engage PLP and lack target specificity, so the strategies for screening alanine racemase inhibitors with an improved impact include targeting the PLP-independent inhibitors that bind to the dimer interface and block dimerization or by placing an inhibitor at the entrance of the catalytic pocket, thereby blocking substrate entry. A promising strategy may be to design or screen inhibitors that bind to the catalytic pocket, targeting the active sites [3].

To discover promising alanine racemase inhibitors that will be useful for developing a novel antibiotic, we proposed a combination experimental and computational screening method. First, we established a screening assay for the identification of smallmolecule inhibitors in a 96-well format using a library of 2100 compounds, followed by antimicrobial susceptibility against $A$. hydrophila, cellular cytotoxicity activity and kinetic studies on the inhibitors. Additionally, the mode of interaction between the inhibitors and the Alr-2 protein was modeled using molecular docking techniques. With these techniques, we developed a novel alanine racemase inhibitor screening method.

\section{Methods}

\section{Bacterial strains, plasmid and culture conditions}

A. hydrophila HBNUAh01 isolated from infected Paralichthys olivaceus [12] and an A. hydrophila alr-2 knockout mutant [13] were used in this study. Escherichia coli BL-21(DE3) cells were used for protein expression. The pET-25b-alr2 plasmid [14] was used for protein expression. The A. hydrophila and E. coli strains were cultured in Luria-Bertani (LB) medium at $30{ }^{\circ} \mathrm{C}$ and $37{ }^{\circ} \mathrm{C}$, respectively. For plasmid selection, $0.5 \mathrm{mmol} / \mathrm{l}$ ampicillin (AMP, Sigma-Aldrich Inc., USA) was added to the LB medium for experiments with $E$. coli.

\section{Compounds and cell culture}

Patulin, D-cycloserine, homogentisic acid and hydroquinone were all purchased from Sigma (Sigma-Aldrich Inc., USA). The HeLa cell line (CCL2 from ATCC) was cultured in RPIM1640 supplemented with $10 \%$ fetal calf serum and a mixture of antibiotics (Penicillin $10^{5} \mathrm{U} / \mathrm{L}$, Streptomycin $100 \mathrm{mg} / \mathrm{L}$ ) under a $5 \% \mathrm{CO}_{2}$ atmosphere.

\section{Purification of alanine racemase}

Alanine racemase was produced and purified as described previously [14]. Pre-cultured BL-21 (DE3) cells with the alr-2 gene cloned in pET-25b (+) $(2 \mathrm{ml})$ were inoculated into $100 \mathrm{ml}$ of fresh $\mathrm{LB}$ culture at $37^{\circ} \mathrm{C}$. Protein overproduction was induced when the cell density at $\mathrm{OD}_{600}$ reached 0.6 by the addition of IPTG at a final concentration of $1 \mathrm{mM}$. The induced cultures were incubated overnight at $28{ }^{\circ} \mathrm{C}$.

The cells were harvested, resuspended into $20 \mathrm{ml}$ of sample buffer (50 mM NaH $\mathrm{PO}_{4}, \mathrm{pH} 8.0,300 \mathrm{mM} \mathrm{NaCl}$, and $10 \mathrm{mM}$ imidazole), and lysed by sonication until a clear lysate was obtained. The crude lysate was centrifuged, and the cell-free supernatant was mixed with $2 \mathrm{ml}$ of 50\% Ni-NTA agarose slurry (Qiagen, Germany) and incubated at $4{ }^{\circ} \mathrm{C}$ for $1 \mathrm{~h}$. Unbound proteins were washed three times with $4 \mathrm{ml}$ of buffer. Bound proteins were eluted four times with $0.5 \mathrm{ml}$ of buffer.

The purified protein was concentrated and dialyzed against the same buffer with $10 \%$ glycerol by ultrafiltration with an Amicon Ultra-15 Centrifugal Filter Device (30 K MWCO, Millipore). The purity and molecular weight of the enzyme were determined by sodium dodecyl sulfate polyacrylamide gel electrophoresis (SDS-PAGE).

\section{Adaptation of the alanine racemase enzyme assay to a 96-well format}

Alanine racemase activity was measured at room temperature in the $\mathrm{L} \rightarrow \mathrm{D}$ direction using a spectrophotometric assay [14]. The assay was modified by varying the volume to $100 \mu \mathrm{l}$ and dividing it into two steps (Fig. 1).

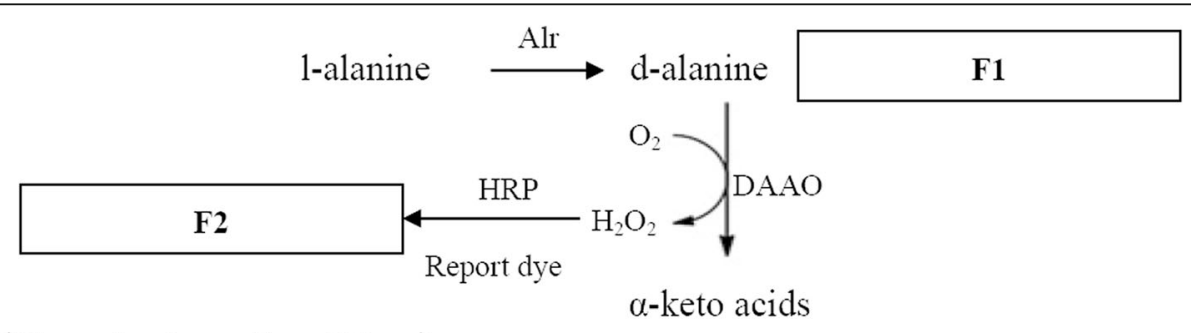

(Blue color formation, $550 \mathrm{~nm}$ )

Fig. 1 Assays for screening alanine racemase-specific inhibitors. Alanine racemase converts L-alanine to D-alanine, providing a substrate for D-amino acid oxidase, which produces hydrogen peroxide. The combination of hydrogen peroxide, horseradish peroxidase, and a dye molecule leads to an insoluble colored product. Fluorescence intensity was measured in a microplate reader 
The first step $\left(\mathrm{F}_{1}\right)$ is the production of the $\mathrm{D}$-form amino acids. The optimized enzyme assay reaction mixture consisted of $10 \mu \mathrm{M}$ PLP, $12.5 \mathrm{mM}$ of $\mathrm{NaHCO}_{3}$ $\mathrm{NaOH}$ buffer ( $\mathrm{pH} 11)$, and $50 \mathrm{mM}$-alanine and alanine racemase. A total of $100 \mu \mathrm{l}$ of this reaction mixture was added to the wells of a 96-well plate. After incubation at $35{ }^{\circ} \mathrm{C}$ for $10 \mathrm{~min}$, the reaction was terminated by adding $12.5 \mu \mathrm{l}$ of $2 \mathrm{M} \mathrm{HCl}$, and the incubation was continued for $2 \mathrm{~min}$ on ice. The reaction mixture was centrifuged at $10,000 \mathrm{RPM}$, for $10 \mathrm{~min}$ at $4{ }^{\circ} \mathrm{C}$, and $10 \mu \mathrm{l}$ of $2 \mathrm{M}$ $\mathrm{NaOH}$ was added to neutralize the reaction mixture. The second step $\left(\mathrm{F}_{2}\right)$ is the conversion of D-alanine to $\alpha$-keto acids using D-amino acid oxidase (DAAO). The formation of $\mathrm{H}_{2} \mathrm{O}_{2}$ from this reaction can be quantified using horseradish peroxidase (HRP) at $550 \mathrm{~nm}$. The DAAO reaction mixture contained $200 \mathrm{mM}$ of Tris- $\mathrm{HCl}$ (pH 8.0), $0.1 \mathrm{mg} / \mathrm{ml}$ 4-aminoantipyrine (AAP), $0.1 \mathrm{mg} /$ $\mathrm{ml} N$-ethyl- $N$-(2-hydroxy-3-sulfopropyl)-m-toluidine sodium salt (TOOS), 2 units of HRP, 0.1 unit of DAAO and D-form amino acid solution in a final volume of $100 \mu \mathrm{l}$. The negative control for the enzyme assay was prepared using the same procedure but without enzyme. After incubating at $37{ }^{\circ} \mathrm{C}$ for $30 \mathrm{~min}$, the absorbance was measured at $550 \mathrm{~nm}$ using a Spectra MAX 190 microplate reader (Molecular Devices Corp., USA). One unit (U) of enzyme was defined as the amount of purified enzyme that catalyzed the formation of $1 \mu \mathrm{mol}$ of D-alanine from L-alanine per minute.

\section{Inhibitor screening procedure}

Each well (sample, control, and their blanks) contained the screening assay reaction mixture of $10 \mu \mathrm{M}$ PLP and $12.5 \mathrm{mM} \mathrm{NaHCO}-\mathrm{NaOH}$ buffer ( $\mathrm{pH} 11)$. Next, $4 \mu \mathrm{l}$ of test substance (small molecular compounds or natural product extracts) was added to the sample and sample blank test tubes. Finally, $2 \mathrm{mM}$ alanine racemase was added to the sample and control test tubes while the same volume of DMSO was added to the sample blank and control blank test tubes. After incubation at $4{ }^{\circ} \mathrm{C}$ for $30 \mathrm{~min}, 50 \mathrm{mM} \mathrm{L}$-alanine was added to the sample and control test wells while DMSO was added to the sample blank and control blank test wells to obtain a final volume of $100 \mu \mathrm{l}$. The control and control blank were defined as $100 \%$ and $0 \%$ of enzyme activity. The reaction was then carried out as described for the alanine racemase assay. The assay is divided into two steps: absorbance was measured at $550 \mathrm{~nm}$ at the end of the first $\left(F_{1}\right)$, and second $\left(F_{2}\right)$ steps and $\Delta F$ was defined as $F_{2}-F_{1}$. Inhibition activity was calculated from the following equation.
Two parameters were used to indicate the quality of the assay: signal-to-noise ratio $(\mathrm{S} / \mathrm{N})$ and the signal-tobackground ratio $(\mathrm{S} / \mathrm{B})$. The $\mathrm{S} / \mathrm{N}$ ratio is classically defined as $\mathrm{S} / \mathrm{N}=$ (mean signal - mean background) $/$ standard deviation of background. The $\mathrm{S} / \mathrm{B}$ ratio is classically defined as $\mathrm{S} / \mathrm{B}=$ mean signal $/$ mean background. The $\mathrm{Z}^{\prime}$ factor is a well-established measure of the assay's quality or suitability, as described previously [15]. The $\mathrm{Z}^{\prime}$ factor is defined by the following formula: $\mathrm{Z}^{\prime}=1-[3(\mathrm{SD}$ sample $+\mathrm{SD}$ control)/ (Mean sample Mean control)], where SD is the standard deviation, the control is the control blank, and $\mathrm{M}$ is the mean.

\section{Compound library}

A library of 2100 natural compounds and the fungal fermentation broths were stored in solution with DMSO. The compound library is from the new drug research and development Co., Ltd. of the North China Pharmaceutical Corporation. The library consists of compounds that were mainly from metabolites of microorganisms.

\section{Enzyme $\mathrm{IC}_{50}$ determination}

Fourfold dilution series (in DMSO) were prepared for all the compounds, and the solutions were added to the wells of a 96-well plate to yield the final inhibitory concentrations. Each concentration was tested in triplicate. The substrate was added after incubation for $30 \mathrm{~min}$, and the fluorescence intensity was measured after the reaction. The positive control (D-cycloserine, DCS) was diluted in DMSO, and the negative control was prepared without adding an inhibitor to the control wells of each plate. Percentage inhibition at each inhibitor concentration was calculated with respect to the negative control. The results were analyzed using the SPSS 16.0 IBM modeler to calculate the compound concentration that causes $50 \%$ inhibition $\left(\mathrm{IC}_{50}\right)$.

\section{Assay interference}

To eliminate the inhibitory effects of the compounds on DAAO and HRP, a counter screening assay was performed as described above. The first-step assay mixtures without alanine racemase and L-alanine were added to each test well, followed by the addition of a twofold dilution series (in DMSO) of the inhibitors to the sample test wells, and finally, the addition of DMSO to the blank control wells. Then, DMSO was added to each well to obtain reaction mixtures at a final volume of $100 \mu \mathrm{l}$.

$$
\text { Inhibition }(I \%)=\frac{[\Delta \mathrm{F}(\text { control })-\Delta \mathrm{F}(\text { control blank })]-[\Delta \mathrm{F}(\text { sample })-\Delta \mathrm{F}(\text { sample blank })]}{\Delta \mathrm{F}(\text { control })-\Delta \mathrm{F}(\text { control blank })} * 100 \%
$$


Second, the D-amino acid oxidase reaction mixture was prepared using $10 \mu \mathrm{M}$ D-ala as the substrate. The control and control blank for the enzyme assay was prepared with or without $10 \mu \mathrm{M}$ D-ala and absorbance was measured at $550 \mathrm{~nm}$.

\section{Antimicrobial susceptibility tests against $A$. hydrophila}

A. hydrophila was cultured for $18 \mathrm{~h}$, washed with PBS $(\mathrm{pH} 7.2)$, and adjusted to an $\mathrm{OD}_{600}$ value of 0.5 . Next, the culture was diluted tenfold five times, and aliquots were spread on LB agar in triplicate to determine the number of colony-forming units $(\mathrm{CFU}) / \mathrm{ml}$.

The minimum inhibitory concentration (MIC) of the chemical compounds against $A$. hydrophila was determined using the microdilution method in accordance with the guidelines of the Clinical and Laboratory Standards Institute, document M31-A3 [16], following the method described by Dal Pozzo et al. [17]. Compounds were diluted in DMSO at concentrations of 80 , 40, 20, or $10 \mu \mathrm{g} / \mathrm{ml}$. Appropriate controls were included in all tests. DCS is a naturally occurring antibacterial compound that targets alanine racemase involved in peptidoglycan synthesis [18]. DCS was used as a positive control (50 and $100 \mathrm{mg} / \mathrm{ml}$ ), DMSO solvent was used as a negative control for growth inhibition and DMSO alone was used as the blank control. All tests were performed in triplicate. The inoculum was prepared in LB culture medium $\left(1 \times 10^{8} \mathrm{CFU} / \mathrm{ml} ; \mathrm{OD}_{600}=0.3\right)$ and cultured at $30{ }^{\circ} \mathrm{C} / 20 \mathrm{~h}$. The inoculum $\left(100 \mu \mathrm{l} ; 1 \times 10^{5} \mathrm{CFU}\right)$ was added to each well containing compounds. The microplates were incubated at $30^{\circ} \mathrm{C}$ for $20 \mathrm{~h}$.

\section{Compound cytotoxicity studies}

This assay was performed in a 96-well plate format and used HeLa cells [19]. The cell viability was determined using 3-(4,5-dimethyl-2-thiazole)-2,5-diphenyl-2H-tetrazolium bromide (MTT, Sigma-Aldrich). Cells were seeded in culture medium in microplates (4000 cells/ well) and incubated at $37{ }^{\circ} \mathrm{C}$ for $24 \mathrm{~h}$ before drug treatments. Compounds were diluted in culture medium to final concentrations of $200,100,50,25,12.5$, or $6.25 \mu \mathrm{g} /$ $\mathrm{ml}$ and added to the cells. The cells were exposed to the compounds for $48 \mathrm{~h}$. At the end of the incubation, the cells were exposed to MTT $(0.5 \mathrm{mg} / \mathrm{ml})$ at $37{ }^{\circ} \mathrm{C}$ for $4 \mathrm{~h}$. The reduced crystals were dissolved in DMSO, and absorbance was detected at $490 \mathrm{~nm}$. The control wells were set as zero absorbance. The percentage of cell survival was calculated using the background-corrected absorbance as follows: Cell survival $(\%)=\left(\mathrm{OD}_{\text {experiment }} /\right.$ $\left.\mathrm{OD}_{\text {control }}\right) \times 100$. The data represent the mean and standard deviation from triplicate determination. The $\mathrm{TC}_{50}$ (the compound concentration that causes $50 \%$ cell death) was calculated using SPSS 16.0 software.

\section{Kinetics of alanine racemase inhibition}

The mode of inhibition of the enzyme by the compounds was determined as follows. The experiment was composed of three sets of reactions in which each set consisted of four concentrations of substrate in the presence of fixed amounts of alanine racemase, and three different concentrations of inhibitors were used. For homogentisic acid and hydroquinone, 0, 0.02 and $0.04 \mathrm{mg} / \mathrm{ml}$ were used. The reactions were made as described [14]. The amount of product was determined spectrophotometrically and subsequently the standard curve was used to obtain reaction velocities. A double reciprocal plot (1/V versus $1 /[\mathrm{S}])$, where $\mathrm{V}$ is reaction velocity and $[\mathrm{S}]$ is substrate concentration, was plotted. The type (mode) of inhibition of enzyme activity by the compounds was determined by analysis of the double reciprocal (Lineweaver-Burk) plot using Michaelis-Menten kinetics. The inhibition constant $\left(K_{\mathrm{i}}\right)$ of the inhibitors was determined.

\section{Molecular docking}

The flexible molecular docking method AutoDock [20] was used to analyze the intermolecular interaction between the Alr-2 protein and the small-molecule inhibitors. In the protocol, the alanine racemase Alr-2 structure was constructed with homology modeling (http://www.swissmodel). The crystal structure of AlaR (PDB IDs: 2rjh.1.A) [21], which has 55.4\% amino acid similarity with Alr-2, was used as a template. The models were built using SWISS-MODEL in the automatic modeling mode and with default parameters. The quality of the models was evaluated using QMEAN and GMQE [22]. To prepare for docking, Gasteiger and Kollman united atom charges were assigned for the inhibitor molecule and the Alr-2 protein, respectively. A polar hydrogen atom was also added to the protein. A grid was set to accommodate the active site region with a $0.375 \AA$ span. The torsion and rotatable bonds in the ligands were defined, and the nonpolar hydrogens and partial atomic charges were added to the bonded carbon atoms [23]. The docking was carried out using the AutoDock Vina program [24] to evaluate ligand binding energies over the conformational search space using the Lamarckian genetic algorithm.

\section{Statistical analysis}

All experimental designs, statistical analyses and graphical representations of data were generated using SPSS 16.0 (SPSS Inc., USA) and the Prism 6.0 software program (GraphPad Software Inc., USA). $\mathrm{IC}_{50}$ data were analyzed by non-linear regression analysis. The $P$ values in the experiments were obtained by using a 2-tailed $t$-test. A $P$ value of $<0.05$ was considered statistically significant. 


\section{Results}

Inhibitor screening results

The assay was adapted from a $200 \mu \mathrm{l}$ format to a $100 \mu \mathrm{l}$ 96-well plate format and optimized. Normal activity was determined in the reaction system and performed in triplicate, with an average OD value of 0.689 . Then, the reaction system was divided in half while maintaining the concentration of each component, and the enzyme activity was determined, with the average OD value of 0.68 . The $\mathrm{S} / \mathrm{B}$ and $\mathrm{S} / \mathrm{N}$ ratios of the assay system were found to be 28 and 32.7, respectively; the calculated value for the screening window coefficient ( $\mathrm{Z}^{\prime}$ factor) was 0.83 . The data indicated that the assay was suitable for inhibitor screening [15].

The library of 2100 compounds was screened in duplicate using final concentrations of 20 and $50 \mu \mathrm{g} / \mu \mathrm{l}$ for compounds and fungal fermentation products, respectively. A graphical representation of the screening results is shown in Fig. 3. Based on a report by Anthony KG et al. [6], compounds showing greater than a $30 \%$ inhibition with respect to the control and control blanks (Fig. 2a) were considered preliminary "hits". We identified 111 compounds from the synthetic compound libraries and 2 compounds from the fungal fermentation broths as hits (Fig. 2a). Based on the percent inhibition of alanine racemase, there were 3 strong (>80\%), 13 intermediate (51-80\%), and 97 weak (30-50\%) inhibitors detected in the library (Fig. 2b).

\section{Further selection criteria for hits and determination of the} $\mathrm{IC}_{50}$ of alanine racemase

All of the hits were retested in a fourfold dilution series. Ten of these compounds specifically inhibited alanine racemase in a dose-dependent manner with more than $50 \%$ inhibition at the highest dose. Table 1 shows the
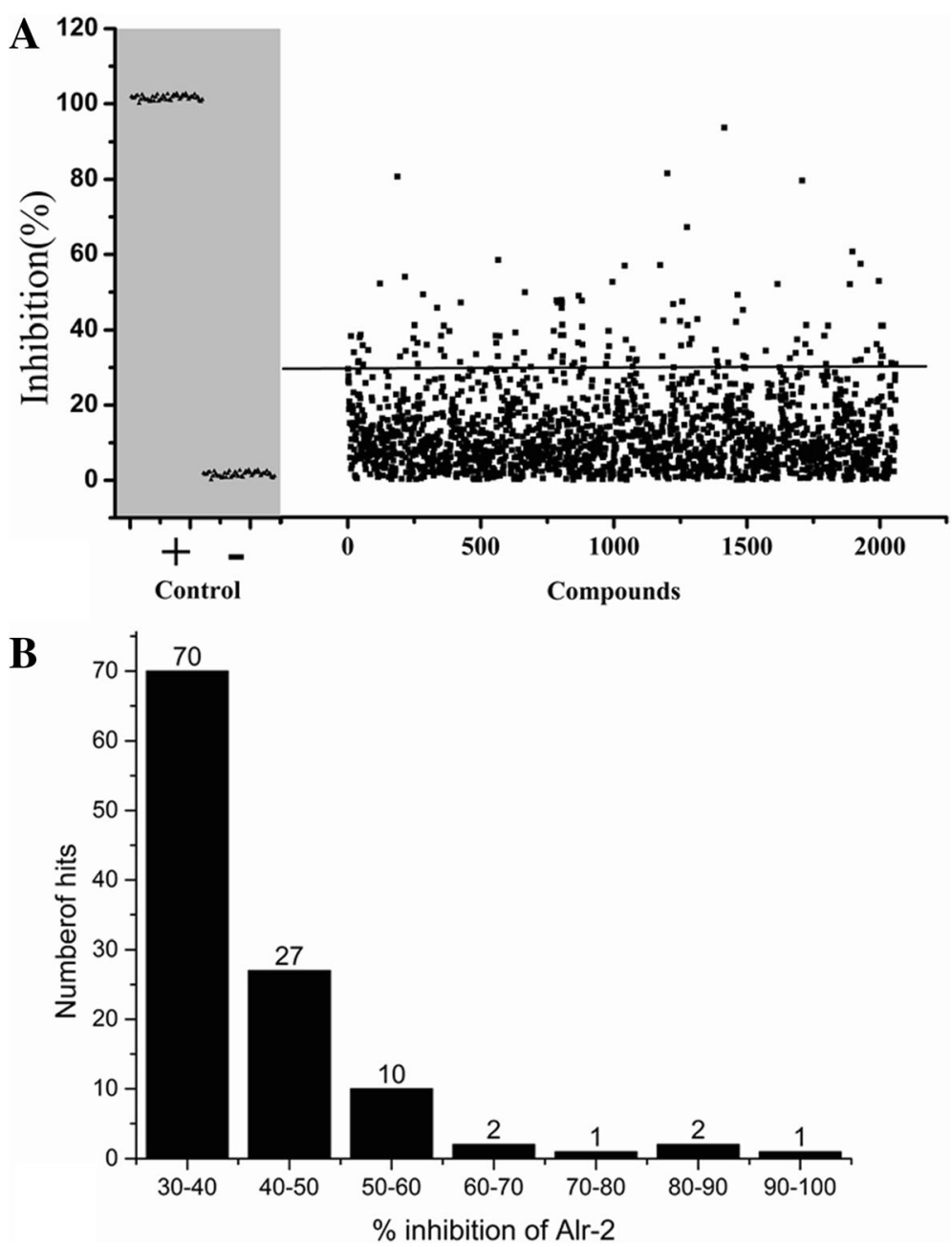

Fig. 2 Summary of the screening results. a Results of positive and negative controls for 96 representative wells of the alanine racemase assay. The positive control represents 100\% inhibition (wells 1-48), and the negative control represents $0 \%$ inhibition in the presence of $1 \%$ DMSO (wells 49-96). Data shown are of two replicates for the entire 2100 compound screen obtained from 96-well plates. b Distribution of the 113 hits, with the hits categorized into 7 groups with respect to percent inhibition 
Table 1 The inhibition values of active compounds for Alr-2

\begin{tabular}{|c|c|c|c|c|c|c|c|c|c|}
\hline Hits & Inhibitor & $\mathrm{MW}$ & Structure & $\begin{array}{l}{ }^{a} \mid C 50 \\
(\mu M)\end{array}$ & $\begin{array}{l}\text { D/C50 } \\
(\mu \mathrm{M})\end{array}$ & $\begin{array}{l}{ }^{c} \mathrm{MIC} \\
(\mu \mathrm{g} / \mathrm{ml})\end{array}$ & $\begin{array}{l}{ }^{\mathrm{d}} \mathrm{MIC} \\
(\mu \mathrm{g} / \mathrm{ml})\end{array}$ & $\begin{array}{l}{ }^{e} \mathrm{TC}_{50} \\
(\mu \mathrm{g} / \mathrm{ml})\end{array}$ & $\mathrm{T}_{\mathrm{i}}$ \\
\hline$\overline{1-1}$ & Anabellamide & 583.626 & & $6.6(0.19)$ & & $\mathrm{NC}$ & $\mathrm{NC}$ & & \\
\hline $1-2$ & Patulin & 154.12 & & $14.7(0.27)$ & & $20(0.89)$ & $80(3.96)$ & NC & NC \\
\hline $1-3$ & Homogentisic acid & 168.147 & & $12.5(0.2)$ & & $120(1.73)$ & $\mathrm{NC}$ & $157.7(6.1)$ & 1.3 \\
\hline $1-4$ & $\begin{array}{l}\text { Acetic acid, }[4-(5-\text { butyl-5-methyl-2(5H)- } \\
\text { furanylidene)dihydro } \\
\text {-3,5-dioxo-2(3H)-furanylidene]-(9Cl) }\end{array}$ & 292.284 & & $8.9(0.34)$ & & NC & $\mathrm{NC}$ & & \\
\hline
\end{tabular}

I-5 Propyl Gallate

1-6 Hydroquinone monohydrochloride

|-8 Haematoxylin

Higenamine
212.2<smiles>CCCOC(=O)c1cc(O)c(O)c(O)c1</smiles>

110.11<smiles>Oc1ccc(O)cc1</smiles>

378.85

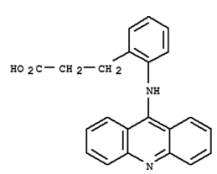

302.29

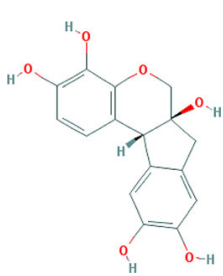

271.32

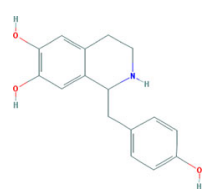

8.6(0.5)

NC NC

18.5(0.18)

$80(2.6)$

140(2.4)

$122.9(8.9) \quad 1.54$

17.7(0.34)

NC

NC

15.6(0.23)

NC

NC

14.3(0.21)
NC 
Table 1 The inhibition values of active compounds for Alr-2 (Continued)

\begin{tabular}{lllllll}
\hline-10 Quercetin & $\mathrm{NC}$ & &
\end{tabular}

NC: non calculable as the values are too high

${ }^{a}$ IC50 against Alr-2 with PLP, average values with standard deviations

${ }^{\mathrm{b}} \mathrm{IC} 50$ against Alr-2 without PLP, average values with standard deviations

${ }^{\mathrm{C}} \mathrm{MIC}$ against $A$.hydrophila, average values with standard deviations

${ }^{\mathrm{d}} \mathrm{MIC}$ against $A$.hydrophila $\Delta$ alr-2, average values with standard deviations

${ }^{\mathrm{e}}$ Cytotoxicity in HeLa cells, average values with standard deviations

${ }^{\mathrm{f}} \mathrm{Ti}=\mathrm{TC}_{50} /{ }^{1} \mathrm{MIC}$

chemical structures of the 10 new alanine racemase inhibitors and their $\mathrm{IC}_{50}$ values. The screening data of ten compounds are shown in the Additional file 1: Figure $\mathrm{S} 1$. The results showed that the $\mathrm{IC}_{50}$ values ranged from 6.6 to $18.5 \mu \mathrm{M}$, with the most potent activity shown by compound I-1. Although these compounds showed high inhibition against alanine racemase, the $\mathrm{IC}_{50}$ values of the compounds were 1.2 to 3.4 times higher than that of DCS.

\section{Antimicrobial activity of alanine racemase inhibitors against $A$. hydrophila}

The ten compounds from above were screened for antimicrobial activity against $A$. hydrophila. The average values with standard deviations in parentheses are shown in Table 1. Three compounds (I-2, I-3, and I-6) were found to inhibit the growth of A. hydrophila significantly. To corroborate these findings, we proceeded to determine the MIC of these compounds using the micro-broth dilution method. Their MICs ranged from 40 to $120 \mu \mathrm{g} / \mathrm{ml}$. Compound I-2 and DCS exhibited a similar MIC.

In our previous paper with A. hydrophila $\Delta a l r-2$, knockout of the alr-2 gene resulted in cell wall damage and enhanced membrane permeability under D-alanine starvation [12]. These results indicated that the alanine racemase Alr-2 is important for A. hydrophila. To determine if the observed growth inhibition was due to the inhibition of alanine racemase Alr-2, we measured the antimicrobial activity against $A$. hydrophila $\Delta a l r-2$. We found that there was a 2-fold increase in the MIC observed for DCS; further, we found a 4-fold and 0.75fold increase for I-2 and I-6, respectively. I-3 had no antimicrobial activity against $A$. hydrophila $\Delta a l r-2$. These results suggest that the antimicrobial activities of I-2 and I-6 might not be due solely to the inhibition of
Alr-2 and that the antimicrobial activity of I-3 was only due to the inhibition of Alr-2 (Table 1).

\section{Assay validation}

To illustrate the counter screen in the second step of the assay, the concentration-inhibition plots for three compounds are indicated (Fig. 3). Compound I-2 has a weak inhibition of the enzymes in the second step; the $\mathrm{IC}_{50}$ values of compounds I-3 and I-6 were 96.1 and $112.92 \mu \mathrm{M}$, respectively, which is more than 8 times their $\mathrm{IC}_{50}$ for alanine racemase. The results eliminated assay interference by the inhibitors.

\section{Cytotoxicity studies of three enzyme inhibitors with antimicrobial activity}

To examine the cytotoxicity of these three enzyme inhibitors, we tested the inhibitors in HeLa cells. The $\mathrm{TC}_{50}$ values are shown in Table 1 . The $\mathrm{TC}_{50}$ for the compounds I-3, I-6, and DCS were 157.7, 122.9 and $149.6 \mu \mathrm{g} / \mathrm{ml} \mathrm{[6],} \mathrm{respectively.} \mathrm{Compound} \mathrm{I-2} \mathrm{exhibits}$ strong cytotoxic effects and reduces the viability of HeLa cells up to $99 \%$ at $6.25 \mu \mathrm{g} / \mathrm{ml}$. Compound I-2 is patulin, which had an $\mathrm{IC}_{50}$ value of $0.62 \mu \mathrm{g} / \mathrm{ml}$ against Caco-2 cells [25]. Compounds I-3 and I-6 are homogentisic acid and hydroquinone. The therapeutic indices $\left(T_{\mathrm{i}}\right)$ of homogentisic acid, hydroquinone and DCS are 1.3, 1.54 and 5 , respectively. The results indicate that homogentisic acid and hydroquinone are potential antimicrobial agents for A. hydrophila.

\section{Determination of inhibition constants}

To gain more insight into the inhibition of alanine racemase by homogentisic acid and hydroquinone, kinetic studies of inhibition were carried out. The LineweaverBurk plots were constructed as shown in Fig. 4. The $K_{\mathrm{m}}$ and $V_{\max }$ of Alr-2 without inhibitors were determined to 

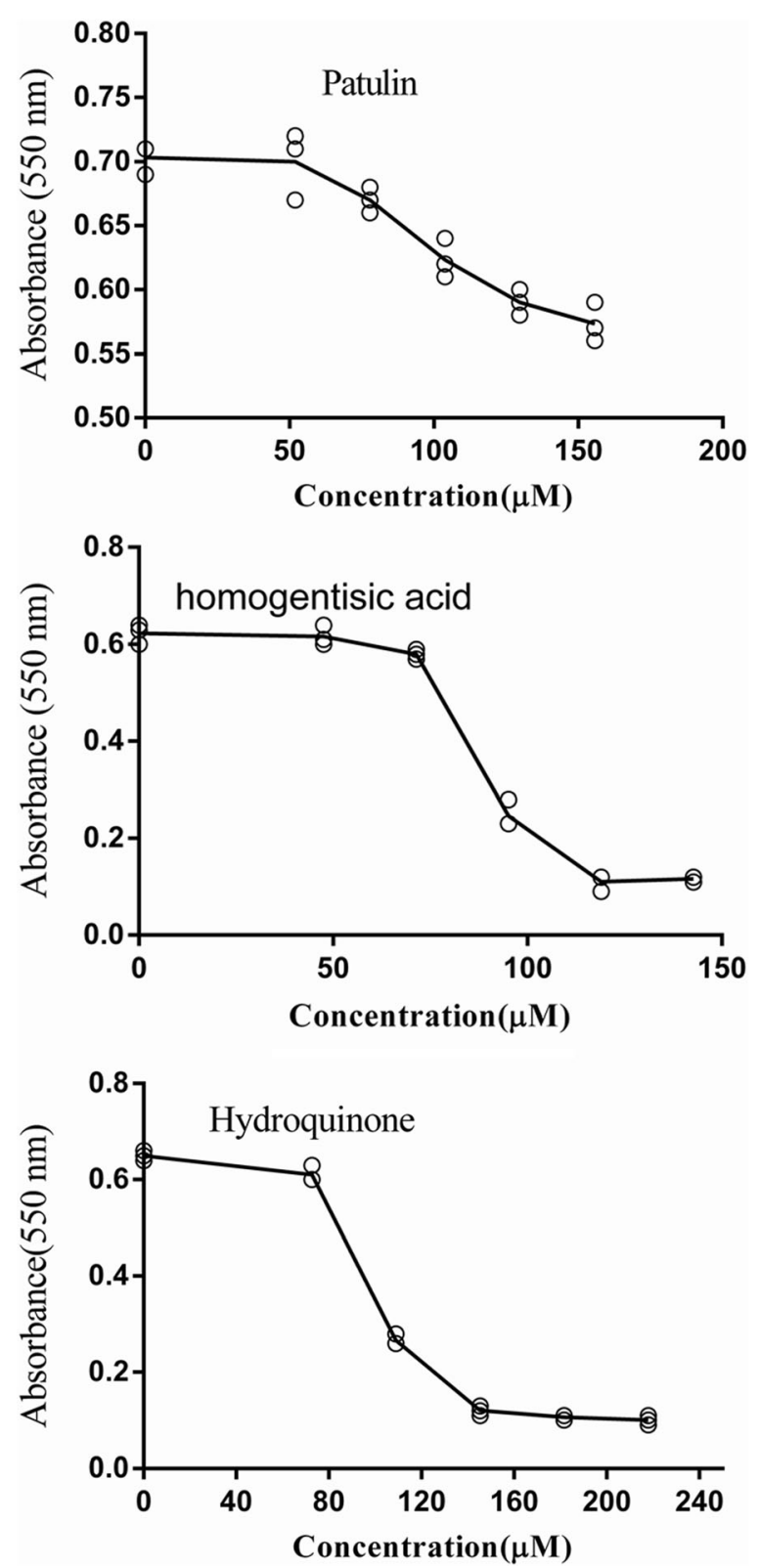

Fig. 3 Counter-screen of three inhibitors. Concentration-response plots are shown for three enzyme inhibitors, (a) patulin; (b) homogentisic acid; (c) hydroquinone. No assay interference was noted for these reagents within a concentration of $50 \mu \mathrm{M}$

be $1.1 \mathrm{mM}$ and $0.94 \mathrm{mM} / \mathrm{min}$, respectively. The Lineweaver-Burk profile of homogentisic acid was of a competitive type of inhibition, while the Lineweaver-Burk profile of hydroquinone was of a noncompetitive type of inhibition. The inhibition constants, $K \mathrm{i}$, were determined to be 51.7 and $212 \mu \mathrm{M}$ for homogentisic acid and hydroquinone, respectively. Based on the above data, we propose that homogentisic acid structurally resembles alanine but is not an alanine analog. Homogentisic acid competitively binds to the enzyme at the active site. Hydroquinone is not structurally similar to alanine and binds to the enzyme or enzyme-alanine at a site where alanine does not bind. Hydroquinone does not compete with alanine for the enzyme.

Docking results of the inhibitors interacting with the Alr-2 protein

Structural coordinates for the Alr-2 protein were predicted using the Swiss-Model server. The best model, made with the protein structure (PDB IDs: 2rjh.1.A) as a template, had the highest structure quality. The GMQE (Global Model Quality Estimation) score was 0.81, and the QMEAN4 score was -2.49. AutoDock, which predicts the direct binding of proteins with small molecules, 


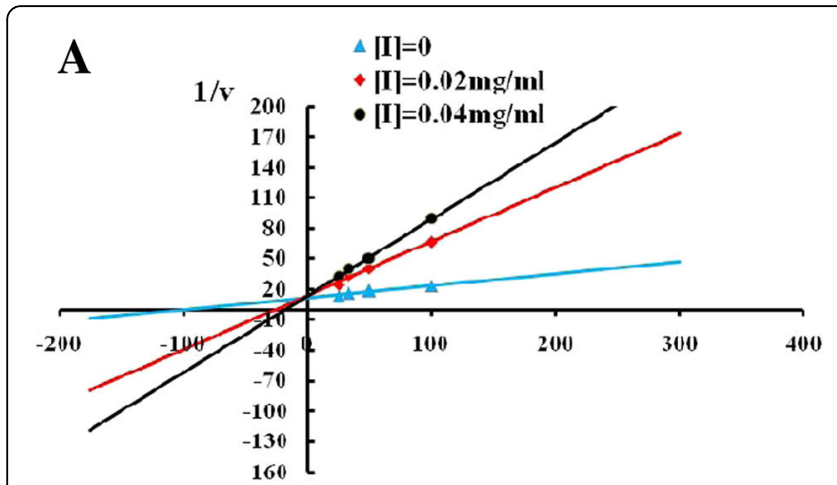

$1 /[\mathrm{s}]$

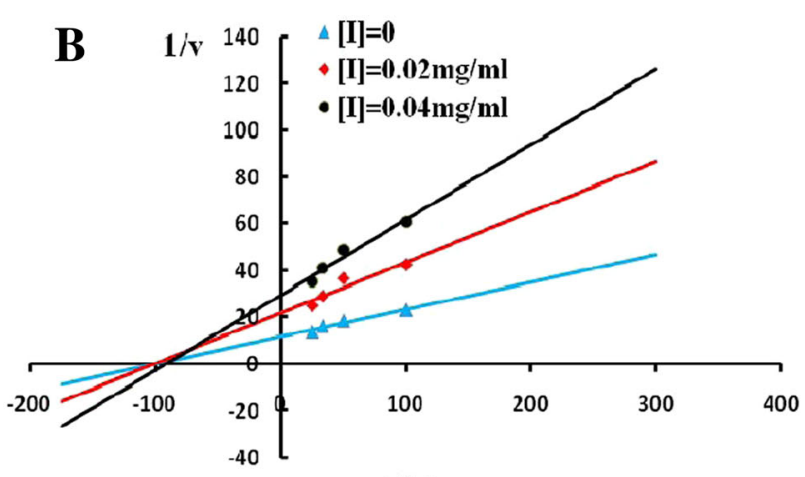

$1 /[\mathrm{s}]$

Fig. 4 Lineweaver-Burk plots of Alr-2 activity assays at different concentrations of homogentisic acid (a) and hydroquinone (b)

was used to verify the possible docking of the inhibitors to Alr-2. Docking results of inhibitors interacting with the Alr-2 protein were shown in Additional file 1: Figure S2-Figure S10. The data suggested that homogentisic acid almost occupies the catalytic active sites of Alr-2, while hydroquinone lies near the active center of Alr-2
(Fig. 5d, e). A change in the binding residues will affect the interaction between the protein and molecules. When the inhibitors occupied the catalytic active sites of Alr-2, PLP could not bind covalently to the active sites. The binding sites of PLP are away from the catalytic center. The LIGPLOT analysis was then introduced to

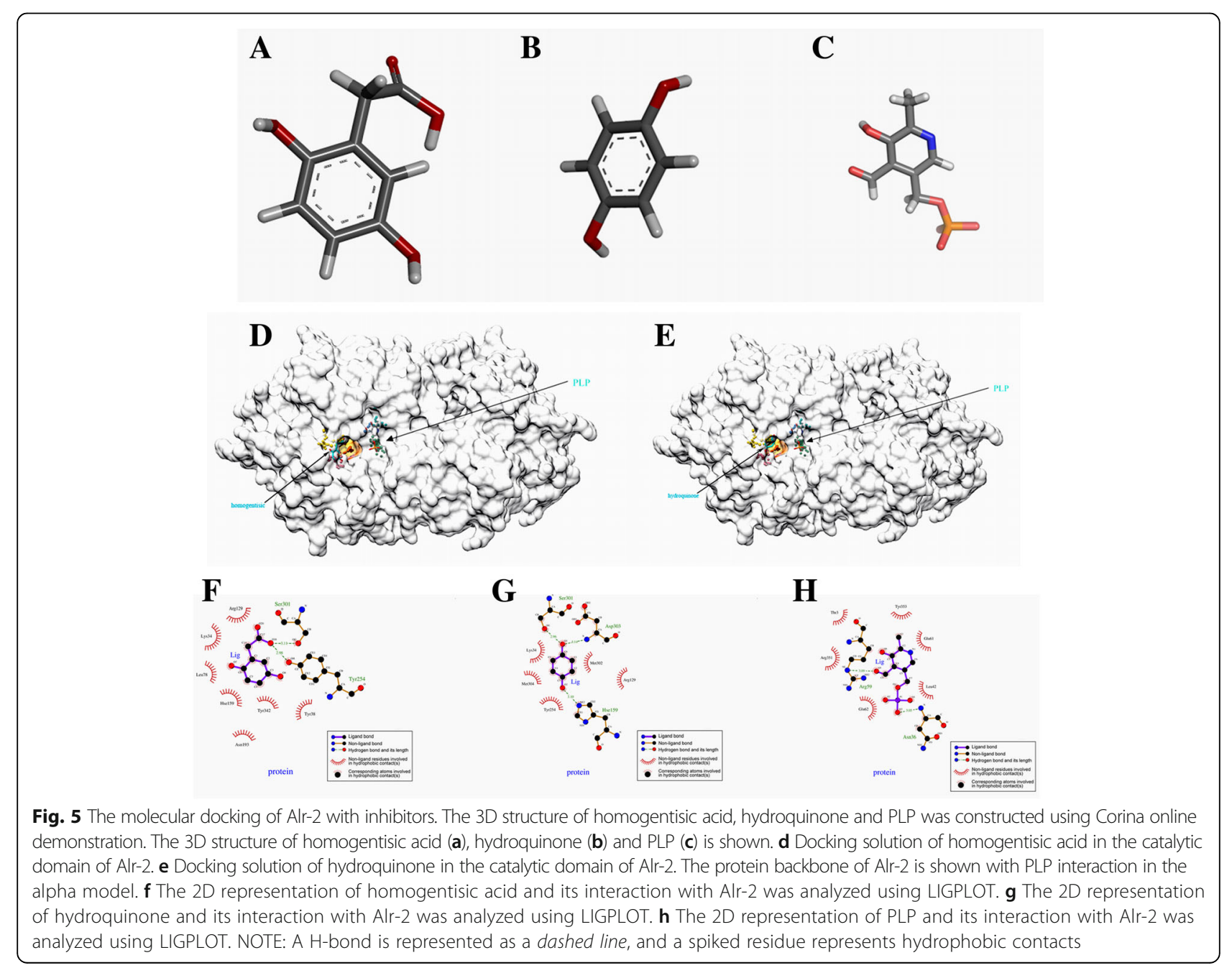


help us understand the in-depth interaction pattern between inhibitors, PLP and the active site residues of the Alr-2 protein. The data showed that homogentisic acid formed hydrogen bonds with Ser301 and Tyr254, which play a major role in the stabilization of the quinonoid intermediate and interacts with the catalytic Lys34 residue and active site residues Tyr38, Tyr342, Leu78, Arg129 and Hse159 in Alr-2. Hydroquinone formed hydrogen bonds with Ser301, Hse159, and Asp304, which are within the active sites of Alr-2, and interacts with the catalytic residues Lys34 and Tyr254 and residues Met304 and Arg129 in the active sites. PLP forms hydrogen bonds with Asn36 and Arg59 and interacts with the Leu42, Glu62, Glu62 Arg351 and Tyr353 residues, which are not in the active sites of the enzyme (Fig. 4f, g). This docking analysis gives a "theoretical quantitative" assessment of the binding efficiencies of inhibitors and proteins.

\section{Discussion}

HTS has been used to screen for a new class of Alr inhibitors. Anthony et al. identified a novel series of Alr inhibitors, developed by high-throughput screening against Mycobacterium tuberculosis for non-substrate analogs, having different mechanisms of enzyme inhibition [6]. The novel enzyme inhibitor thiadiazolidinone was obtained, which inhibits the growth of methicillinresistant Staphylococcus aureus (MRSA) [26], M. tuberculosis and M. smegmatis [27]. Willies SC et al. developed a high-throughput screening method for alanine racemase activity that can be identified in a solid format [28]. In this study, we improved the enzyme assay method of Willies to be a liquid phase assay for alanine racemase inhibitor screening and this assay has proved effective according to the screening and assay interference results.

The compound library is important for inhibitor screening. Anthony et al. used a library of 53,000 small molecules, including therapeutic compounds and natural compounds, for inhibitor screening in their study [6]. They found seven compounds that were active against $M$. tuberculosis and with minimal cytotoxicity against HeLa cells. In the present study, the compounds in the library were mainly the metabolites of microorganisms.

The majority of identified alanine racemase inhibitors, however, are suicide substrates that react with the enzyme cofactor and tend to inhibit other PLP-containing enzymes indiscriminately. In this study, we found several novel inhibitors that are not alanine analogs. The antibacterial activities and cytotoxicity noted for two of the inhibitors (homogentisic acid and hydroquinone) are non-substrate-like enzyme inhibitors and potential antibiotics for $A$. hydrophila. Homogentisic acid is a product of phenylalanine and tyrosine metabolism in a wide variety of higher organisms. Homogentisic acid actively inhibited the growth of eight species of gram-negative oral bacteria $[29,30]$. Hydroquinone has antimicrobial activity against MRSA, methicillin-sensitive $S$. aureus (MSSA) and E. coli (BL) 21 in alkaline conditions [31, 32]. However, these compounds also have adverse side effects in humans. In patients with a rare autosomal recessive disorder, an accumulation of homogentisic acid leads to Alkaptonuria [33]. Hydroquinone is a toxic compound of Agaricus hondensishas and widely used in skin lightening (bleaching) cosmetics and toiletries. Abuse of hydroquinone will result in adverse side effects and complications $[34,35]$. It is the first time the antimicrobial activity of homogentisic acid and hydroquinone against $A$. hydrophila has been confirmed.

The earliest drug development for alanine racemase was carried out in the absence of a crystal structure and resulted in the development of a small, covalent inhibitor, cycloserine. Cycloserine interacts with the enzymebound PLP and interferes with the catalytic process of the enzyme [36]. Although the MIC values of homogentisic acid and hydroquinone is 3-5 times higher than that of DCS, they directly interact with the active sites of alanine racemase. These compounds, unlike DCS, do not inactivate other unrelated PLP-dependent enzymes and are potential antimicrobials against $A$. hydrophila.

The small-molecule screening approach has been successfully used for HTS of bacterial targets. Many effective inhibitors to these targets were identified and these compounds inhibit the target by many mechanisms [7]. Alanine racemase is an important target for antibacterial drug design as it is a key enzyme in peptidoglycan biosynthesis and bacterial cell wall formation. The reason most inhibitors of alanine racemase are not used clinically is because they lack specificity and target other PLP-dependent enzymes. One of the representative inhibitors is DCS, a restricted drug against tuberculosis with serious side effects on the nervous system [37]. This emphasizes the need for the development of new inhibitors for Alr with greater specificity that may in turn translate into less toxicity to humans.

Numerous molecular modeling studies of alanine racemase inhibitors have been published. Scaletti ER et al. successfully purified, crystallized, determined the structure and performed a kinetic characterization of Staphylococcus aureus alanine racemase from the Mu50 strain (AlrSas), which exhibits resistance to both methicillin and glycopeptide antibiotics. Structural examination indicates that the active site binding pocket, dimer interface and active site entryway of the enzyme are potential targets for structureaided inhibitor design. This structural and biochemical information provides a template for future structure-based drug-development efforts targeting AlrSas [38]. To determine the specific inhibitors that act on the active sites of the enzyme from $A$. hydrophila, we performed a systematic computational analysis to identify inhibitor- 
protein interactions through molecular docking. Finally, we identified two compounds that could interact with the active sites of alanine racemase and would make effective inhibitors. These inhibitors have never been reported.

\section{Conclusions}

The results presented in this study suggested an efficient combination of experimental and computational methods for the screening of Aeromonas hydrophila alanine racemase Alr-2 inhibitors. The inhibitor-protein interactions exhibited by the inhibitors could be applied to the development of new antibiotics against $A$. hydrophila.

\section{Additional file}

Additional file 1: Figure S1. The second screening dataset of ten compounds screened in the inhibitor screening. Figure S2. The RMSD fluctuation profile of the modeled protein over 20 ns MD simulations. Figure S3. The superposed structures clustered from MD simulations. Figure S4. The top binding mode of hydroquinone calculated from Dock6. Figure S5. The top binding mode of hydroquinone calculated from AutoDock Vina. Figure S6. The top binding mode of hydroquinone calculated from AutoDock 4. Figure S7. The top binding mode of homogentisic acid calculated from Dock6. Figure S8. The top binding mode of the homogentisic acid calculated from AutoDock Vina. Figure S9. The top binding mode of the homogentisic acid calculated from AutoDock 4. Docking results of the Alr-2 protein interacting with alanine. Figure S10. The top binding mode of the alanine calculated from AutoDock Vina. (DOC $4146 \mathrm{~kb})$

\section{Abbreviations}

A. hydrophila: Aeromonas hydrophila; AAP: 4-aminoantipyrine; AMP: Ampicillin; CFU: Colony-forming units; DAAO: D-amino acid oxidase; DCS: D-cycloserine; DMSO: Dimethyl sulfoxide; GMQE: Global model quality estimation; homogentisic acid: 2,5-Dihydroxyphenylacetic acid; HRP: Horseradish peroxidase; $I C_{50}$ : 50\% Inhibitory concentration; $K_{\mathrm{i}}$ : Inhibition constant; LB: Luria-Bertani; MICs: Minimal inhibitory concentrations; MRSA: Methicillinresistant Staphylococcus aureus; MSSA: Methicillin sensitive S. aureus; MTT: 3-(4,5-dimethyl-2-thiazole)-2,5-diphenyl-2H-tetrazolium bromide; PLP: Pyridoxal-5'-phosphate; S/B: Signal-to-background ratio; S/N: Signalto-noise ratio; $T_{\mathrm{i}}$ : Therapeutic indices; TOOS: $\mathrm{N}$-ethyl- $\mathrm{N}$-(2-hydroxy-3sulfopropyl)-m-toluidine sodium salt

\section{Acknowledgments}

We thank Dr. Murtala Muhammad for his advice and assistance in writing our article.

\section{Funding}

This research was supported by grants from the Natural Science Foundation of Hebei Province (C2013205103), the Out-standing youth Foundation of the Department of Education of Hebei Province (YQ2014026), the Research Fund of Hebei Normal University (L2016Z03) and the State Key Laboratory of Pathogen and Biosecurity (Academy of Military Medical Science) (SKLPBS1529).

\section{Availability of data and materials}

The data generated or analyzed during this study are included in this published article. Additional data are available from the corresponding author on reasonable request.

\section{Authors' contributions}

$Y W, B Z$ and DL proposed the study and assessed and interpreted the results. $\mathrm{YW}, \mathrm{XL}$, and $\mathrm{WX}$ executed the experiments; DL prepared the manuscript, $\mathrm{CY}$ completed the modeling and docking experiments and interpreted the results. $\mathrm{JJ}$ and TZ assisted in the compound cytotoxicity studies and the inhibition kinetics analysis. All authors read and approved the final manuscript.

\section{Competing interests}

The authors declare that they have no competing interests.

\section{Consent for publication}

Not applicable.

Ethics approval and consent to participate

Not applicable.

\section{Publisher's Note}

Springer Nature remains neutral with regard to jurisdictional claims in published maps and institutional affiliations.

\section{Author details}

${ }^{1}$ College of Life Science, Hebei Normal University, Shijiazhuang, China.

2Department of Chemistry, New York University, New York, NY 10003, USA.

Received: 8 November 2016 Accepted: 13 April 2017

Published online: 25 May 2017

\section{References}

1. Singh V, Chaudhary DK, Mani I, Jain R, Mishra BN. Development of diagnostic and vaccine markers through cloning, expression, and regulation of putative virulence-protein-encoding genes of Aeromonas hydrophila. J Microbiol. 2013:51:275-82

2. Hossain MJ, Waldbieser GC, Sun D, Capps NK, Hemstreet WB, Carlisle K, et al Implication of lateral genetic transfer in the emergence of Aeromonas hydrophila isolates of epidemic outbreaks in channel catfish. PLoS One. 2013:8:e80943.

3. Azam MA, Jayaram U. Inhibitors of alanine racemase enzyme: a review. J Enzyme Inhib Med Chem. 2015;29:1-10.

4. Sharma V, Gupta P, Dixit A. In silico identification of putative drug targets fromdifferent metabolic pathways of Aeromonas hydrophila. In Silico Biol. 2008:8:331-8.

5. di Salvo ML, Florio R, Paiardini A, Vivoli M, D'Aguanno S, Contestabile R. Alanine racemase from Tolypocladium inflatum: a key PLP-dependent enzyme in cyclosporine biosynthesis and a model of catalytic promiscuity. Arch Biochem Biophys. 2013:529:55-65.

6. Anthony KG, Strych U, Yeung KR, Shoen CS, Perez O, Krause KL, Cynamon $\mathrm{MH}$, Aristoff PA, Koski RA. New classes of alanine racemase inhibitors identified by high-throughput screening show antimicrobial activity against Mycobacterium tuberculosis. PLoS One. 2011;6:e20374.

7. Im H, Sharpe ML, Strych U, Davlieva M, Krause KL. The crystal structure of alanine racemase from Streptococcus pneumoniae, a target for structurebased drug design. BMC Microbiol. 2011;11:116

8. Kim MG, Strych U, Krause K, Benedik M, Kohn H. Evaluation of aminosubstituted heterocyclic derivatives as Alanine Racemase inhibitors. Med Chem Res. 2003;12:130-8.

9. Kim MG, Strych U, Krause K, Benedik M, Kohn H. N (2)-substituted D, $\mathrm{L}$-cycloserine derivatives: synthesis and evaluation as alanine racemase inhibitors. J Antibiot. 2003;56:160-8.

10. Toney MD. Reaction specificity in pyridoxal phosphate enzymes. Arch Biochem Biophys. 2005;433:279-87.

11. Radkov AD, Moe LA. Bacterial synthesis of D-amino acids. Appl Microbiol Biotechnol. 2014;98:5363-74

12. Li N, Sun YM, Tian LY, Zhao BH. The isolation and identification of Aeromonas hydrophila. J Hebei Normal Univ /Nat Sci Ed. 2009;33:240-3.

13. Liu D, Zhang L, Xue W, Wang YP, Ju JS, Zhao BH. Knockout of the alanine racemase gene in Aeromonas hydrophila HBNUAh01 results in cell wall damage and enhanced membrane permeability. FEMS Microbiol Lett. 2015; 362: fnv089. doi: 10.1093/femsle/fnv089.

14. Liu D, Liu XP, Zhang L, Jiao HW, Ju JS, Zhao BH. Biochemical characteristics of an alanine racemase from Aeromonas hydrophila HBNUAh01. Microbiology. 2015;84:202-9

15. Zhang $\mathrm{JH}$, Chung TD, Oldenburg KR. A simple statistical parameter for use in evaluation and validation of high throughput screening assays. J Biomol Screen. 1999:4:67-73.

16. Clinical Laboratory Standards Institute. Antimicrobial disk and dilution susceptibility tests for bacteria isolated from animals. Approved standard, 3rd ed. Wayne: CLSI; 2008. CLSI Document M31-A3. 


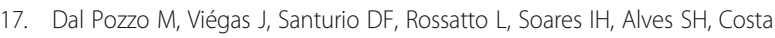
MM. Atividade antimicrobiana de óleos essenciais decondimentos frente a Staphylococcus sp. isolados de mastite caprina. Ciênc Rural. 2011:41:667-72.

18. Feng ZY, Barletta RG. Roles of Mycobacterium smegmatis D-alanine:D-alanine ligase and D-alanine racemase in the mechanisms of action of and resistance to the peptidoglycan inhibitor D-cycloserine. Antimicrob Agents Chemother. 2003;47:283-91.

19. Mosmann T. Rapid colorimetric assay for cellular growth and survival: application to proliferation and cytotoxicity assays. J Immunol Methods. 1983;65:55-63.

20. Goodsell DS, Olson AJ. Automated docking of substrates to proteins by simulated annealing. Proteins. 1990;8:195-202.

21. Wu D, Hu T, Zhang L, Chen J, Du J, Ding J, Jiang H, Shen X. Residues Asp164 and Glu165 at the substrate entryway function potently in substrate orientation of alanine racemase from E. coli: enzymatic characterization with crystal structure analysis. Protein Sci. 2008;17:1066-76.

22. Arnold K, Bordoli L, Kopp J, Schwede T. The SWISS-MODEL workspace: a web-based environment for protein structure homology modelling. Bioinformatics. 2006;22:195-201.

23. Ni Z, Jin X, Zhou P, Wu Q, Lin XF. A combination of computational and experimental approaches to investigate the binding behavior of B.sub lipase a mutants with substrate $p$ NPP. Mol Inform. 2011:30:359-67.

24. Trott O, Olson AJ. AutoDock Vina: improving the speed and accuracy of docking with a new scoring function, efficient optimization, and multithreading. J Comput Chem. 2010;31:455-61.

25. Ciustea M, Mootien S, Rosato AE, Perez O, Cirillo P, Yeung KR, Ledizet M, Cynamon MH, Aristoff PA, Koski RA, Kaplan PA, Anthony KG. Thiadiazolidinones: a new class of alanine racemase inhibitors with antimicrobial activity against methicillin-resistant Staphylococcus aureus. Biochem Pharmacol. 2012;83:368-77.

26. Willies SC, White JL, Turner NJ. Development of a high-throughput screening method for racemase activity and its application to the identification of alanine racemase variants with activity towards L-arginine. Tetrahedron. 2012;68:7564-7.

27. Lupescu A, Jilani K, Zbidah M, Lang F. Patulin-induced suicidal erythrocyte death. Cell Physiol Biochem. 2013;32:291-9.

28. Lee Y, Mootien S, Shoen C, Destefano M, Cirillo P, Asojo OA, Yeung KR, Ledizet M, Cynamon MH, Aristoff PA, Koski RA, Kaplan PA, Anthony KG. Inhibition of mycobacterial alanine racemase activity and growth by thiadiazolidinones. Biochem Pharmacol. 2013;86:222-30.

29. Frases S, Salazar A, Dadachova E, Casadevall A. Cryptococcus neoformans Can utilize the bacterial melanin precursor homogentisic acid for fungal Melanogenesis. Appl Environ Microbiol. 2007;73:615-21.

30. Fukamachi $\mathrm{H}$, Matsumoto $\mathrm{C}$, Omiya $\mathrm{Y}$, Arimoto T, Morisaki $\mathrm{H}$, Kataoka $\mathrm{H}$, Kadena M, Funatsu T, Fukutake M, Kase $Y$, Kuwata $H$. Effects of Hangeshashinto on growth of oral microorganisms. Evid Based Complement Alternat Med. 2015;2015:12947.

31. Chaaban I, Khawass ESME, Mahran MA, Razik HAAE, Salamouni NSE, Wahab AEA. Synthesis and biological evaluation of novel hydroquinone dimethyl ethers as potential anticancer and antimicrobial agents. Med Chem Res. 2013;22:3760-78

32. Guo JY, Hong ZG, Zhang LL, Wu HG, Dou CZ. Preliminary study the effects of semiquinone radicals on bacteriostatic activity. China J Tradit Chin Med Pharm. 2014;29:3427-31.

33. Phornphutkul C, Introne WJ, Perry MB, et al. Natural history of alkaptonuria. N Engl J Med. 2002;347:2111-21.

34. Olumide YM, Akinkugbe AO, Altraide D, Mohammed T, Ahamefule N, Ayanlowo S, Onyekonwu C, Essen N. Complications of chronic use of skin lightening cosmetics. Int J Dermatol. 2008:47:344-53.

35. Joval E, Kroeger P, Towers N. Hydroquinone: the toxic compound of Agaricus hondensis. Planta Med. 1996:62:185.

36. Weinstein L. Antimicrobial agents: drugs used in the chemotherapy of tuberculosis and leprosy. In The pharmacological basis of therapeutics. 5 edition. In: Goodman LS, Gilman A, Editors. New York: Macmillan Publishing Co. Inc; 1975:1201-1223.

37. Newton RW. Side effects of drugs used to treat tuberculosis. Scott Med J. 1975;20:47-9.

38. Scaletti ER, Luckner SR, Krause KL. Structural features and kinetic characterization of alanine racemase from Staphylococcus aureus (Mu50) Acta Crystallogr D Biol Crystallogr. 2012;68:82-92.

\section{Submit your next manuscript to BioMed Central and we will help you at every step:}

- We accept pre-submission inquiries

- Our selector tool helps you to find the most relevant journal

- We provide round the clock customer support

- Convenient online submission

- Thorough peer review

- Inclusion in PubMed and all major indexing services

- Maximum visibility for your research

Submit your manuscript at www.biomedcentral.com/submit 